\title{
Porous, robust highly conducting Ni-YSZ thin film anodes prepared by magnetron sputtering at oblique angles for application as anodes and buffer layers in solid oxide fuel cells
}

Francisco J. Garcia-Garcia $^{a}$, Francisco Yubero ${ }^{a}$, Agustin R. González-Elipe ${ }^{a}$, Stella P. Balomenou $^{\mathrm{c}}$, Dimitris Tsiplakides ${ }^{\mathrm{b}, \mathrm{c}}$, Ioanna Petrakopoulou ${ }^{\mathrm{b}, \mathrm{c}}$, and Richard M. Lambert ${ }^{\mathrm{a}, \mathrm{d}^{*}}$

${ }^{a}$ ICMSE (CSIC - Universidad Sevilla) Américo Vespucio 49, E-41092 Sevilla, Spain

${ }^{b}$ Department of Chemistry, Aristotle University of Thessaloniki, GR-54124 Thessaloniki, Greece

${ }^{c}$ Chemical Process \& Energy Resources Institute (CPERI), Centre for Research and Technology-Hellas (CERTH), Thessaloniki, GR-57001 Thessaloniki, Greece

${ }^{d}$ Chemistry Department, Cambridge University, Lensfield Road, Cambridge, CB2 1EW, UK.

* corresponding author; rml1@ cam.ac.uk; Tel +44 1223 336467; Fax +44 1223336362

\begin{abstract}
Uniform, highly porous, columnar thin films incorporating YSZ and NiO prepared by magnetron sputtering with deposition at glancing incidence exhibited stoichiometries close to that of the YZr-Ni sputter target. Characterization by means of SEM, XRD, XPS and RBS revealed that the uniformly distributed nickel component in the as-deposited films consisted of $\mathrm{NiO}$, and that the YSZ component was essentially amorphous. Annealing such films at $850^{\circ} \mathrm{C}$ in hydrogen resulted in crystallization of the YSZ phase with preservation of the columnar morphology, while the NiO underwent reduction to metallic $\mathrm{Ni}$, which partially segregated to the film surface. The hydrogenannealed thin film anodes exhibited high conductivity, comparable to that of conventionallyprepared anodes, in both hydrogen and hydrogen/water mixtures at temperatures relevant to SOFC operation. They were also robust against strain-induced separation from the substrate under limited thermal cycling in both oxidizing and reducing atmospheres and are promising candidates for use as anodes in their own right and as strain-accommodating buffer layers between conventional anodes and the electrolyte for use in SOFC applications.
\end{abstract}

Keywords magnetron sputtering, oblique angle deposition, Ni-YSZ, thin film anodes, SOFC

\section{Introduction}

The merits of solid oxide fuel cells for application in distributed power or combined heat and power generation are well known: for an authoritative review see [1]. However, due to the high operating temperatures required, a number of materials-related problems remain to be overcome 
in order to achieve satisfactory long-term performance [2]. In the case of the anode, which has to be porous and must provide adequate electronic conductivity, a key issue concerns device failure associated with the thermal expansion/contraction mismatch that is necessarily present at the electrolyte/anode interface [3-4]. Typical anodes consist of Ni-YSZ cermets of about $100 \mu \mathrm{m}$ thicknesses with a metal content of at least $30 \mathrm{vol} \%$ [5].

Both DC and RF magnetron sputtering employing a variety of configurations have previously been used for Ni-YSZ anode fabrication with a view to investigating optimum deposition conditions (although high temperature performance was not reported) [6-7], improving resistance [8] or optimising microstructure and efficiency by application of asymmetric bipolar pulsed magnetrons [9]. In the latter comprehensive study the microstructure obtained was similar to that reported here, although we have used a simpler technique in conjunction with oblique angle deposition to produce highly porous anodes characterized by good three phase boundaries and excellent resistance to delamination at the anode/electrolyte interface under thermal cycling in oxidizing and reducing atmospheres.

The intrinsic problem due to thermal mismatch is exacerbated by the fact that the higher the Ni content the greater the thermal expansion of the anode cermet. Here we describe the preparation, detailed characterization and electrical testing of very thin film anode cermets of well controlled structure prepared by DC magnetron sputtering at oblique angles [10, 11]. The aim was to achieve good adhesion with the substrate, thus minimising thermal stress-induced fracture and separation problems associated with conventionally applied thick anode cermets. It was found that our materials, which are a few microns thick, exhibit superior electrical characteristics compared to conventional Ni-YSZ anodes. Moreover, they are robust against thermal cycling and so offer considerable promise for use as buffer layers between conventional anodes and the electrolyte in order to mitigate the common problem of loss of adhesion at the electrolyte/anode interface that occurs under operating conditions, while at the same time providing good electrical conduction. They also signpost the development of graded Ni-YSZ anodes where the film composition varies between that of pure YSZ electrolyte and that of an overlying conventional ( $30 \% \mathrm{Ni}$-YSZ) anode cermet in order to provide optimum materials accommodation and hence enhanced long-term thermal stability at the electrolyte/anode interface.

\section{$2 \quad$ Materials and Methods}

Thin film preparation.

Ni-YSZ porous thin films were prepared by reactive pulsed DC magnetron sputtering $(200 \mathrm{~W}, 80$ 
$\mathrm{kHz}$, base pressure $3 \times 10^{-6} \mathrm{mbar}$ ). The pressure during deposition was maintained at $5 \times 10^{-3}$ mbar in a process gas that consisted of $40 \mathrm{sccm}$ Ar and $2.5 \mathrm{sccm} \mathrm{O}$. Pellets of pressed YSZ powder (from fuelcellmaterials.com) were used as the substrates for conductivity measurements, whereas a silicon substrate was used for RBS, XRD and XPS studies to ensure that $\mathrm{Y}$ and $\mathrm{Zr}$ signals were exclusively due to the thin film anode. A $50 \mathrm{~mm}$ diameter NiZrY target was used under oblique angle deposition conditions with a target-substrate distance of $\sim 5 \mathrm{~cm}$ and an angle of $80^{\circ}$ between the target and substrate normals, which gave a deposition rate of $1.5 \mu \mathrm{m} \mathrm{h}^{-1}$. The target consisted of a Ni/Zr/Y alloy (68.8/26.6/4.6 wt.\%) of 99.9\% purity, chosen to achieve YSZ films containing $8 \mathrm{~mol} \% \mathrm{Y}_{2} \mathrm{O}_{3}$ and $50 \mathrm{vol} \% \mathrm{Ni}$. A more detailed description of the deposition procedure may be found in references [12-14] and a schematic of the experimental set-up is shown in the supporting information (Figure S1). The use of an oblique angle deposition configuration resulted in the formation of highly porous anode thin films, crucial for achieving superior structural and electrical properties. The technique was very reproducible, as is well known [9], all sample preparations and analyses having been repeated at least twice.

\section{Ex situ thin film characterization.}

The microstructure of films deposited on doped silicon (100) wafers was examined by scanning electron microscopy (SEM) using a Hitachi S4800 field emission microscope. These samples allowed straightforward dicing for cross-sectional analysis. Rutherford back scattering spectrometry (RBS) spectra were obtained in a tandem accelerator (Centro Nacional de Aceleradores, Universidad de Sevilla, Spain) with $\alpha$ particle energy $1.557 \mathrm{MeV}$, beam current and diameter $1.7 \mathrm{nA}$ and $\sim 1 \mathrm{~mm}$, respectively. The accumulated dose was $1.5 \mu \mathrm{C}$ in all cases and spectra were analysed by means of the SIMRA6.0 program. X-ray diffraction (XRD) patterns were obtained using $\mathrm{Cu} \mathrm{K} \alpha$ radiation with a Panalytical X'Pert Pro diffractometer incorporating a diffracted beam graphite monochromator and 1D silicon strip detector (X'Celerator). They were recorded from $2 \theta 10^{\circ}$ to $90^{\circ}$ with step size $0.026^{\circ}$ at 148 s per step. Analyses were performed using XPert HighScore Plus software. XPS spectra were recorded with a ESCALAB 210 instrument working with a constant pass energy of $20 \mathrm{eV}$. In accord with common practice, the binding energy (BE) scale is referenced to the $\mathrm{C}$ 1s peak $(284.5 \mathrm{eV})$ arising from adventitious carbon. In-plane conductivity measurements were performed using the Van der Pauw method [14] under either dry or wet $\left(3 \% \mathrm{H}_{2} \mathrm{O}\right)$ hydrogen atmosphere in the temperature range 800 to $900^{\circ} \mathrm{C}$. Further details are provided in the supporting information (Figure S2 and Table S1).

\section{Results and Discussion}


Figure 1 shows a representative RBS spectrum along with the corresponding simulated spectrum. The spectrum exhibits three peaks corresponding, from right to the left, to $\mathrm{Y}+\mathrm{Zr}$, $\mathrm{Ni}$ and $\mathrm{O}$. Because the atomic numbers of $\mathrm{Y}$ and $\mathrm{Zr}$ elements are close, their RBS peaks overlap. Accordingly, the results are presented in terms of the sum of these two elements. Simulation of the spectrum yields the concentrations of the uniformly distributed elements within the film (Table 1). The resulting Ni: $\mathrm{Y}+\mathrm{Zr}$ ratio was close to that reported for optimized sintered anodes prepared by conventional methods. Moreover, the Y:Zr ratio measured by EDX (supporting information, Table S2) was also close to that reported for optimized, sintered, conventionally prepared anodes [1-2]. The oxygen content of the films obtained by RBS was measurably higher than would be expected for a pure Ni component, indicating that the nickel within the as-prepared films was partially or fully oxidised.

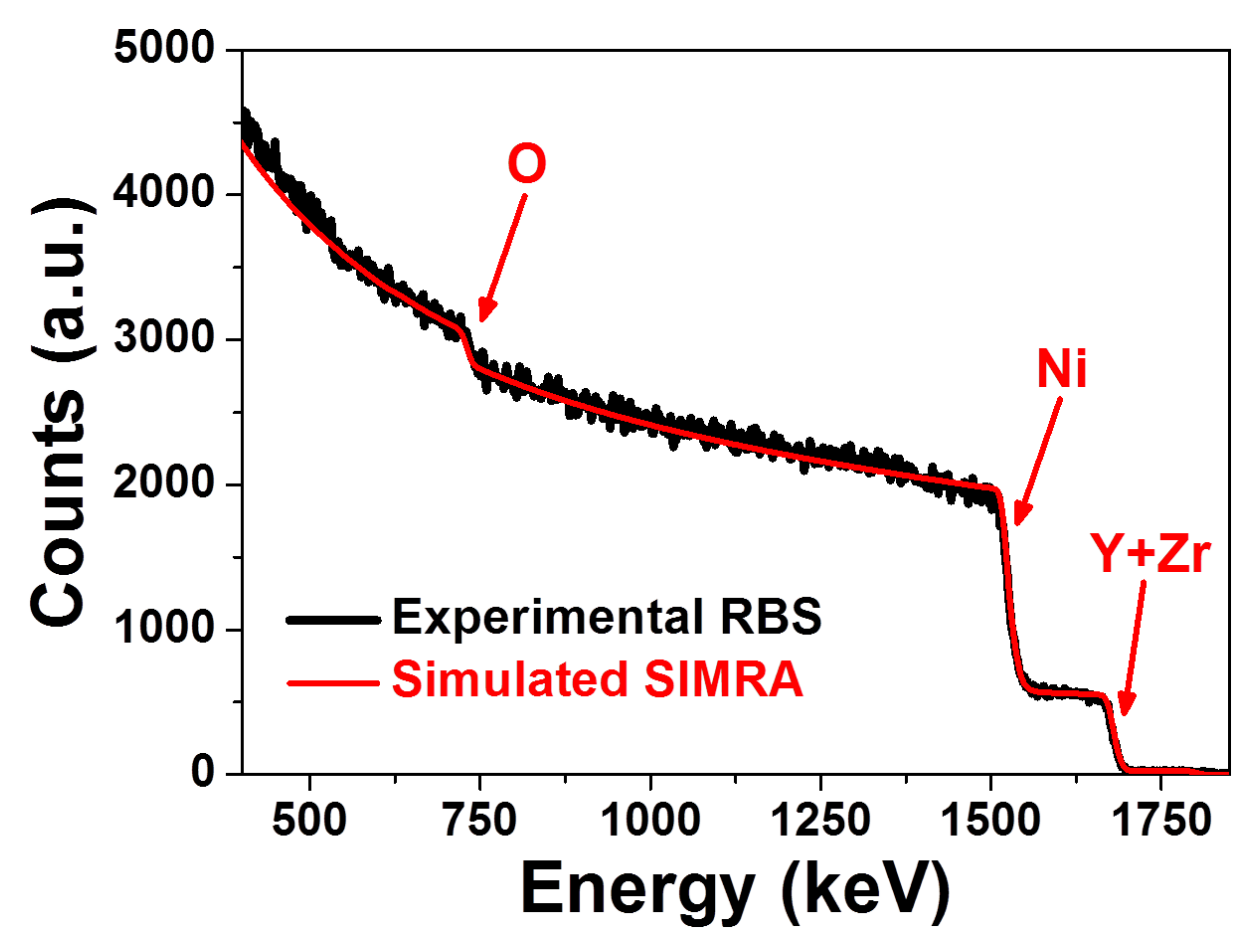

Figure 1. RBS experimental and SIMRA (http://home.rzg.mpg.de/ mam/) simulated spectra of Ni-YSZ thin film. Si substrate.

Table 1.- Concentrations of elements in the thin film.

\begin{tabular}{|l|l|l|l|l|}
\hline & $\begin{array}{l}\text { Thickness } \\
\left(\mathbf{1 0} \mathbf{a t}^{\mathbf{1 5}} \mathbf{c m}^{\mathbf{2}}\right)\end{array}$ & $\begin{array}{l}\text { Ni } \\
(\% \text { at. })\end{array}$ & $\begin{array}{l}\text { Y+Zr } \\
(\% \text { at. })\end{array}$ & $\begin{array}{l}\text { O } \\
(\% \text { at. })\end{array}$ \\
\hline YSZ:Ni & $19500 \pm 1000$ & $34.0 \pm 3.0$ & $6.5 \pm 0.8$ & $59.5 \pm 5.0$ \\
\hline
\end{tabular}


This latter conclusion is in line with XPS and XRD measurements on the as-deposited sample, described in detail below.

Figure 2 shows typical SEM images of the surface and cross-section of Ni-YSZ thin films asdeposited $(\boldsymbol{a}, \boldsymbol{c})$, and after heating in hydrogen $\left(850^{\circ} \mathrm{C}, 3 \mathrm{~h}\right)$ to achieve complete reduction of the Ni component $(\boldsymbol{b}, \boldsymbol{d})$. The as-deposited film surface exhibited a granular morphology with small grains of about $10-50 \mathrm{~nm}$. The clearly visible larger scale cracks are presumably due to strain relief. The cross-section $(\boldsymbol{c})$ of the as-deposited thin film showed a well developed columnar microstructure $\sim 2.5 \mu \mathrm{m}$ thick with a porosity of $\sim 33 \%$ [10-14]. The tilted orientation of the nanocolumns is due to enhancement of shadowing effects resulting from oblique incidence geometry employed [16].

After heating in hydrogen (Figure $2(\boldsymbol{b}, \boldsymbol{d})$ ) nickel segregation occurred yielding a bimodal distribution of large $(1.5-6 \mu \mathrm{m})$ and small $(200-400 \mathrm{~nm})$ polycrystalline Ni particles located atop the film surface and also within the film itself, with preservation of the columnar structure, the associated high porosity, and now a favorable three phase boundary, conducive to good anode performance. The Ni particles themselves were comprised of $\sim 69 \mathrm{~nm}$ crystallites (Scherrer formula; (111) diffraction peak; Fig 3) consistent with observations reported elsewhere [6,9].
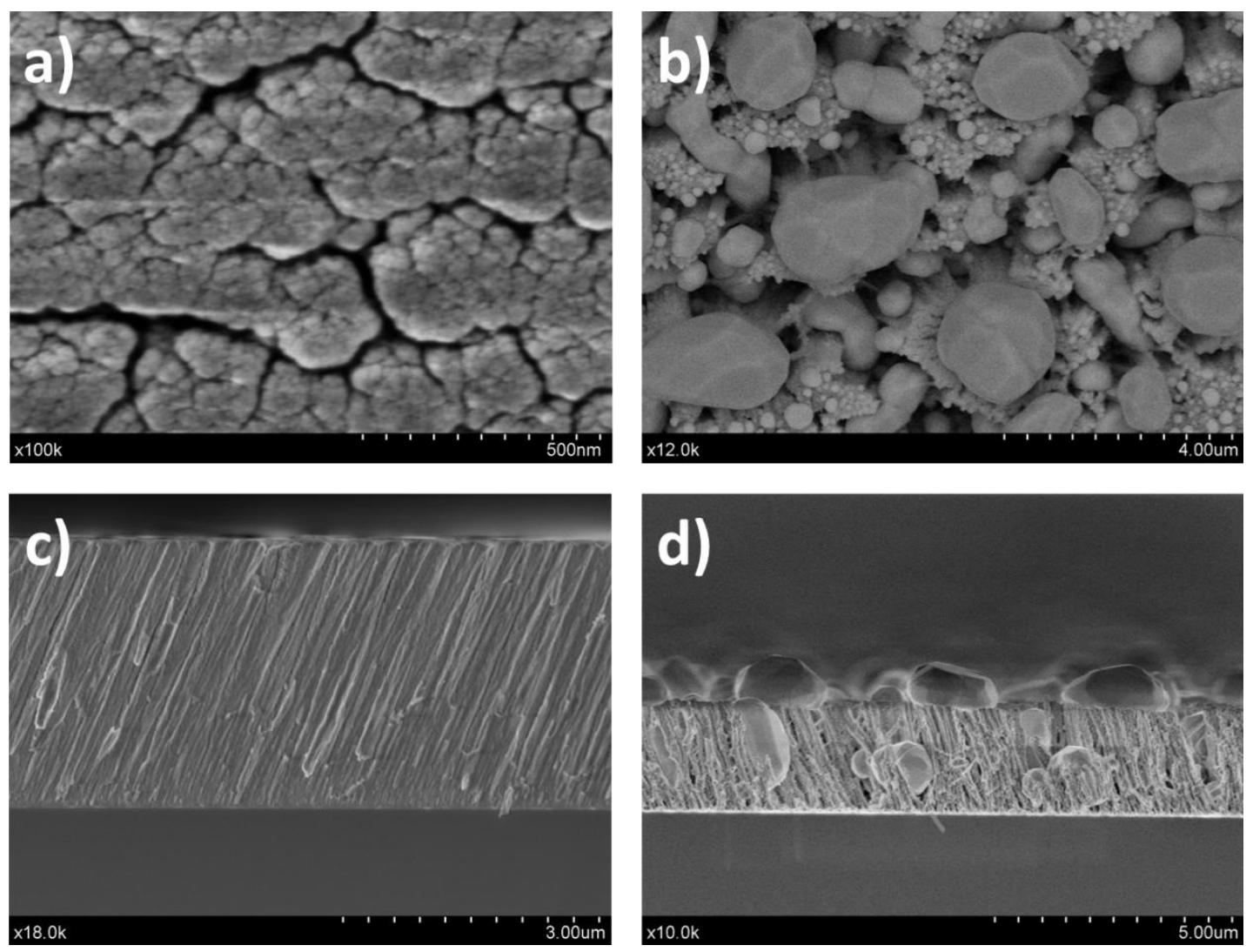
Figure 2.- Top view $(\boldsymbol{a})$ and cross section $(\boldsymbol{c})$ of the as-deposited thin film and after hydrogen-annealing $(\boldsymbol{b}, \boldsymbol{d})$. Silicon substrate.

Figure 3 shows XRD data for an as-deposited thin film and for the same film after heating in hydrogen at $1{ }^{\circ} \mathrm{C} / \mathrm{min}$ to $850^{\circ} \mathrm{C}$ with gradual increase of hydrogen concentration from $24 \%$ to $100 \%$. The purpose of this treatment was to create the necessary percolation path between $\mathrm{Ni}$ particles and thus facilitate electron conductivity. The effectiveness of the treatment is confirmed by SEM images shown in Figure 2, where the evolution of the electrically conductive path is evident. The as-deposited film shows no evidence for the presence of crystalline YSZ and it is clear that the Ni was present as an oxide. However, after heat treatment in hydrogen, the reduced samples exhibited well defined peaks attributable to metallic Ni and to YSZ, in good accord with the segregation of metallic nickel observed in the SEM images (Figure $2 \mathbf{b , d}$ ). Rietveld analysis confirmed that YSZ was present as the cubic phase (PDF 30-1468) $a=b=c=5.1342 \AA$ and $\alpha=\beta=\gamma=90^{\circ}$.

These findings are also consistent with $\mathrm{Ni} 2 \mathrm{p}$ photoemission spectra (supporting information, Figure S3) from the as-deposited and hydrogen-annealed films. Because the XP spectra were recorded $e x s i t u$, necessitating exposure to air, the hydrogen-annealed spectrum is a convolution of contributions from $\mathrm{Ni}^{0}$ and $\mathrm{Ni}^{2+}$. The $\mathrm{Ni} 2 \mathrm{p}$ spectrum obtained after hydrogen-annealing was substantially more intense (about 3 times) than that from the as-deposited sample, again pointing to surface segregation of the agglomerated Ni component in the former case. 


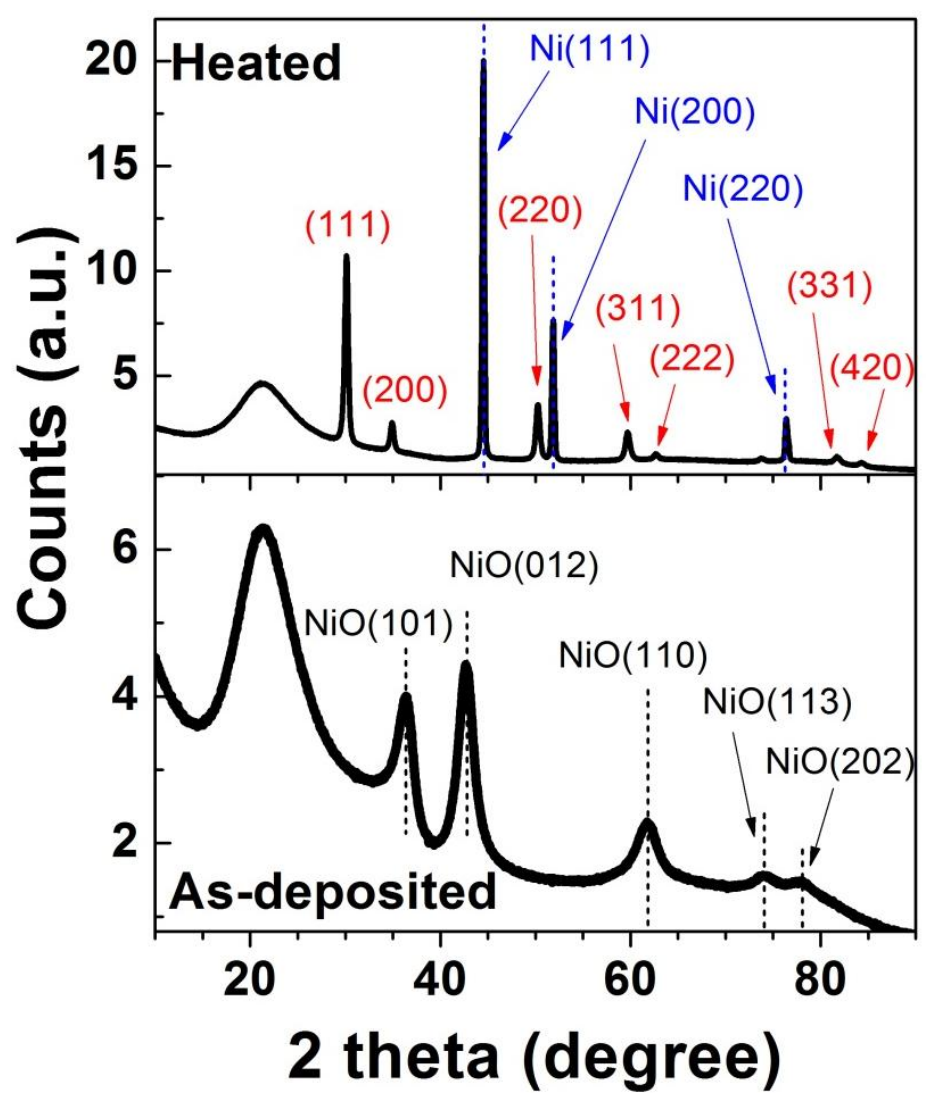

Figure 3.- XRD diagrams of Ni-YSZ thin films as-deposited and after hydrogen-annealing (red and blue labels refer to YSZ and Ni respectively). Silicon substrate.

In order to verify good percolation and consequently good current collection, the anode in-plane conductivity was evaluated. Four point Van der Pauw measurements were carried out at $800{ }^{\circ} \mathrm{C}$ and $900{ }^{\circ} \mathrm{C}$ in both dry and humidified hydrogen (Table 2). Further details are given in the supporting information. The total conductivity of Ni-YSZ cermets depends strongly on $\mathrm{Ni}$ content. More specifically, it is found that the conductivity of the cermet as a function of nickel content exhibits an S-shaped curve, as predicted by percolation theory $[5,17,18]$. The percolation threshold for the conductivity of the cermet occurs at about 30 vol \% nickel, depending on preparation method and film porosity $[5,19,20]$. The concentration of $\mathrm{Ni}$ in our thin film as measured by RBS (Table 1), is $34.0 \pm 3.0$ at.\%. Given that the subsequent heat treatment under reducing conditions caused segregation of metallic nickel to the film surface (Figure 2), the eventual concentration of $\mathrm{Ni}$ in the cermet is expected to be close to the lower limit of its conductivity threshold. Thus the behaviour of our sputtered Ni-YSZ thin film anodes is entirely comparable with that of conventionally (screen printed) cermets, where for example a conductivity of $3 \mathrm{~S} \cdot \mathrm{cm}^{-1}$ was reported for a $\sim 30 \%$ at. Ni-YSZ anode [5] at a higher temperature $\left(1000{ }^{\circ} \mathrm{C}\right)$, and by us for a commercially supplied anodes operated in the same equipment under 
the same conditions (dry and humidified H2 and at 800 and $900 \mathrm{C}$ ) (see supporting information, Table S2).

Finally, we examined the resistance of our anodes to delamination resulting from strain-induced thermal cycling - an important characteristic with regard to practical applications. Three different protocols were used for anode thin films deposited on YSZ substrates, as follows: (i) heating to $850{ }^{\circ} \mathrm{C}$ in $\mathrm{Ar} / \mathrm{H}_{2}(3 \mathrm{~h})$, then cooled (ii) procedure (i) followed by heating to $1250{ }^{\circ} \mathrm{C}$ in air (2h), then cooled (iii) procedure (i) then procedure (ii) followed by heating to $850{ }^{\circ} \mathrm{C}$ in $\mathrm{Ar} / \mathrm{H}_{2}(3 \mathrm{~h})$. The results are illustrated in Figure 4 (a)-(c) from which it apparent that full integrity of the structure was retained with no changes in morphology nor any discernible separation of the anode from the underlying electrolyte. In passing we note that others have previously used magnetron sputtering to deposit YSZ electrolyte films on commercial Ni-YSZ anodes - in effect the inverse of what we report here [21-22]. It was found that the thin film electrolyte/commercial anode interfaces maintained their structures under operating condition; note however that our systems are more complex and in principle more demanding in that they involve the deposition and subsequent processing of a ternary $\mathrm{Y}-\mathrm{Zr}-\mathrm{Ni}$ system.
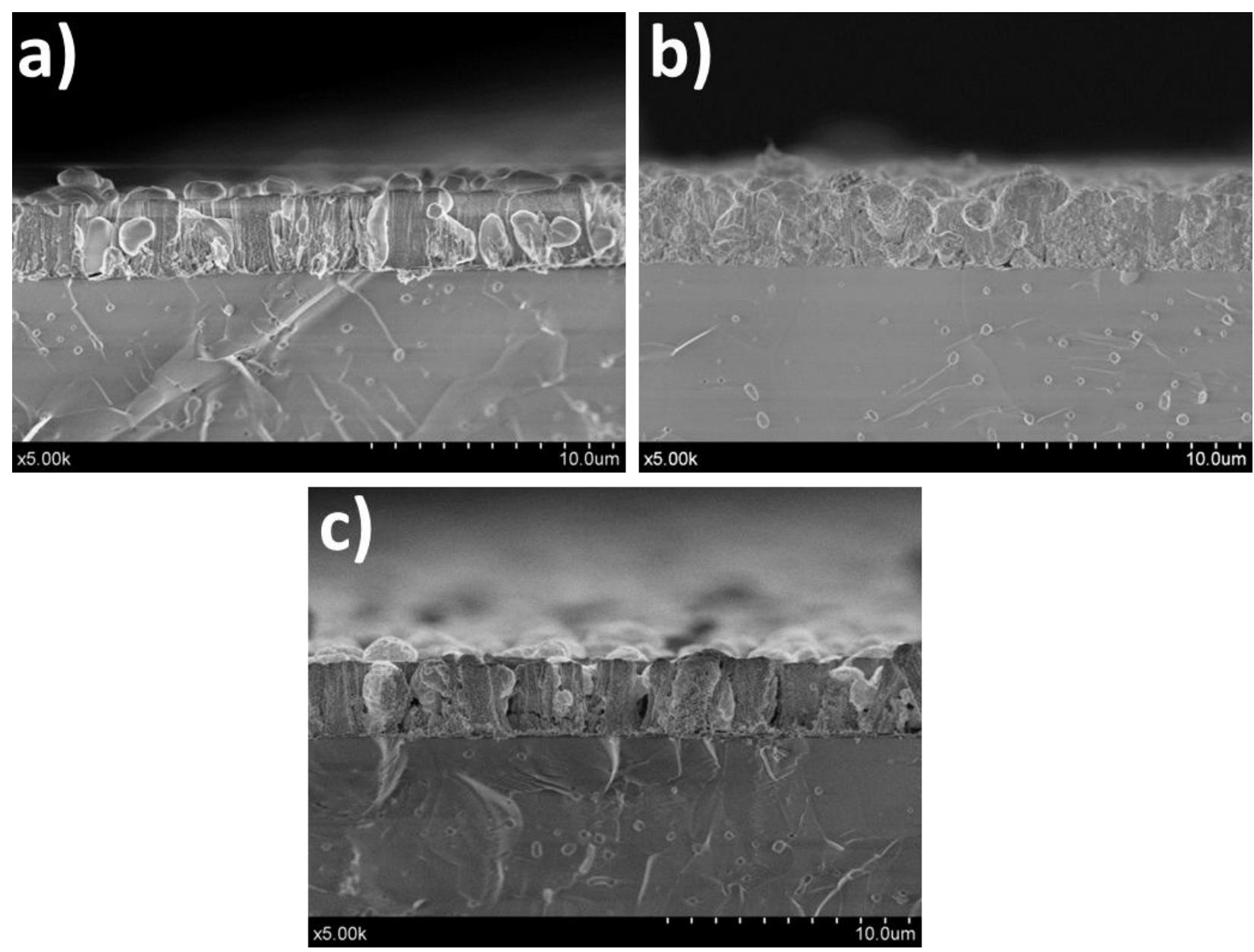
Figure 4 Thin film cross sections after procedures i (a), ii (b) and iii (c) respectively. YSZ substrate.

Thus in terms of both electrical characteristics and robustness our sputtered thin films are promising candidates for use not only as strain-relieving buffer layers between conventional anodes and the YSZ electrolyte but also for the fabrication of graded Ni-YSZ composite anodes, with a controlled $\mathrm{Ni}$ content and film porosity. Their good electronic conductivity may be attributed to the presence of a large three-phase boundary (TPB) due to the high porosity and exceptionally good interconnectivity of the YSZ and Ni phases. Recall that the TPB is of crucial importance to the performance of SOFCs - a large TPB yields high electrochemical performance [23].

Table 2.- Surface conductivity of thin film anodes

\begin{tabular}{|c|c|}
\cline { 2 - 2 } \multicolumn{1}{c|}{} & Conductivity (S/cm) \\
\hline $800^{\circ} \mathrm{C}$, dry $\mathrm{H}_{2}$ & 2.40 \\
\hline $800^{\circ} \mathrm{C}, 3 \% \mathrm{H}_{2} \mathrm{O} / \mathrm{H}_{2}$ & 2.45 \\
\hline $900^{\circ} \mathrm{C}, \operatorname{dry~} \mathrm{H}_{2}$ & 2.86 \\
\hline $900^{\circ} \mathrm{C}, 3 \% \mathrm{H}_{2} \mathrm{O} / \mathrm{H}_{2}$ & 2.96 \\
\hline
\end{tabular}

\section{Conclusions}

Uniform, highly porous, columnar thin films incorporating YSZ and NiO may be prepared by magnetron sputtering deposition at oblique incidence angle. The nickel content within the asdeposited films is uniformly distributed and the YSZ component is essentially amorphous.

Annealing the as-deposited films at $850^{\circ} \mathrm{C}$ in hydrogen resulted in crystallization of the YSZ phase with preservation of the columnar morphology. At the same time the $\mathrm{NiO}$ underwent reduction to metallic $\mathrm{Ni}$, which then segregated to the film surface as $0.7-2.0 \mu \mathrm{m}$ particles.

The hydrogen-annealed thin film anodes exhibited good conductivity in both hydrogen and hydrogen/water mixtures at temperatures relevant to SOFC operation. Moreover, under limited thermal cycling in both oxidizing and reducing atmospheres, they were robust against morphological changes and delamination from an underlying YSZ substrate. Accordingly, because their thinness renders them robust against strain-induced separation from the substrate, they are also promising candidates for use as highly conducting, stabilising buffer layers for 
accommodating strain between conventional anodes and the YSZ electrolyte, and for fabrication of graded-composition Ni-YSZ anodes for use in SOFC applications.

\section{$4 \quad$ Acknowledgements}

The research leading to these results has received funding from the European Union's Seventh Framework Programme (FP7/2007-2013) for the Fuel Cells and Hydrogen Joint Technology Initiative under the T-CELL project with grant agreement $n^{\circ}$ 298300. Support from a MINECO (Spain), grant $n^{\circ}$ MAT2013-40852R, is also acknowledged.

\section{$5 \quad$ References}

[1] Ormerod R.M. Solid oxide fuel cells. Chem Soc Rev 2003;32:17.

[2] Matsuzaki Y., Yasuda I. The poisoning effect of sulfur-containing impurity gas on a SOFC anode: Part I. Dependence on temperature, time, and impurity concentration. Solid State Ionics 2000:132;261.

[3] Fischer W., Malzbender J., Blass G., Steinbrech R.W. Residual stresses in planar solid oxide fuel cells. J Power Sources 2005:150; 73.

[4] Ma Q., Tietz F., Leonide A., Ivers-Tiffée E. Anode-supported planar SOFC with high performance and redox stability. Electrochem Commun 2010:12;1326.

[5] Dees D.W., Clark T.D., Easler T.E., Fee D.C., Mrazek F.C. Conductivity of porous nickel/zirconium dioxide-yttrium sesquioxide cermets. J Electrochem Soc 1987:134;2141.

[6] Rezugina E., Thomann A.L., Hidalgo H., Brault P., Dolique V., Tessier Y. Ni-YSZ films deposited by reactive magnetron sputtering for SOFC applications. Surf Coat Tech 2010:204;2376.

[7] Jou S., Wu T-H. Thin porous Ni-YSZ films as anodes for a solid oxide fuel cell. J Phys Chem Solids 2008:69;2804.

[8] Tsai T., Barnett S.A. Sputter deposition of cermet fuel electrodes for solid oxide fuel cells. J Vac Sci Technol A 1995:13;1073.

[9] Solovyev A.A., Sochugov N.S., Rabotkin S.V., Shipilova A.V., Ionov I.V., Kovalchuk A.N., Borduleva A.O. Application of PVD methods to solid oxide fuel cells. Appl Surf Sci 2014:310;272.

[10] Alvarez R, García-Martin J.M., López-Santos M.C., Rico V., Ferrer F.J., Cotrino J., A.R. González-Elipe A.R., Palmero A. On the deposition rate of magnetron sputtered thin films at oblique angles. Plasma Proc Polymers 2014:11; 511 
[11] Gonzalez-Garcia L., Parra-Barranco J., Sanchez-Valencia J.R., Barranco A., Borras A., Gonzalez-Elipe A.R., Garcia-Gutierrez M.C., Hernandez J.J., Rueda D.R., Ezquerra T.A. Correlation lengths, porosity and water adsorption in $\mathrm{TiO}_{2}$ thin films prepared by glancing angle deposition. Nanotechnology 2012; 23: 205701

[12] Gil-Rostra J., Cano M., Pedrosa J.M., Ferrer F.J., García-García, F.J., Yubero F., GonzálezElipe A.R. Electrochromic behavior of $\mathrm{W}_{\mathrm{x}} \mathrm{Si}_{\mathrm{y}} \mathrm{O}_{\mathrm{z}}$ thin films prepared by reactive magnetron sputtering at normal and glancing angles. ACS Appl Mater Interfaces 2012;4:628.

[13] Garcia-Garcia F.J., Gil-Rostra J., Yubero F., González-Elipe A.R., Electrochromism in $\mathrm{WO}_{\mathrm{x}}$ and $\mathrm{W}_{\mathrm{x}} \mathrm{Si}_{\mathrm{y}} \mathrm{O}_{\mathrm{z}}$ thin films prepared by magnetron sputtering at glancing angles. Nanosci Nanotechnol Lett 2013;5:89.

[14] Gil-Rostra J., García-García F., Yubero F., González-Elipe, A.R. Tuning the transmittance and the electrochromic behavior of $\mathrm{Co}_{x} \mathrm{Si}_{y} \mathrm{O}_{z}$ thin films prepared by magnetron sputtering at glancing angle. Sol Energy Mater Sol Cells 2014;123:130.

[15] Van der Pauw L.J. A method of measuring specific resistivity and Hall effect of disc of arbitrary shape. Philips Res Rep 1958:13;1.

[16] Alvarez R, Lopez-Santos C., Parra-Barranco J., Rico V. Barranco A., Cotrino J., GonzalezElipe A.R., Palmero A. Nanocolumnar growth of thin films deposited at oblique angles: Beyond the tangent rule. J Vac Sci Technol B 2014; 32: 041802

[17] Minh N.Q., Takahashi T.: Science and Technology of Ceramic Fuel Cells, Elsevier 1995.

[18] Ivers-Tiffee E., Wersing W., Schiessl M., Greiner H. Ceramic and metallic components for a planar SOFC. Ber Bunsenges Phys Chem 1990:94;978.

[19] Vivet N., Chupin S., Estrade E., Richards A., Bonnamy S., Rochais D., Bruneton E. Effect of Ni content in SOFC Ni-YSZ cermets: A three-dimensional study by FIB-SEM tomography. J Power Sources 2011:196;9989.

[20] Lee J.-H., Moon H., Lee H.-W., Kim J., Kim J.-D., Yoon K.-H. Quantitative analysis of microstructure and its related electrical property of SOFC anode, Ni-YSZ cermet. Solid State Ionics 2002:148; 15 .

[21] Coddet P., Pera M.-C., Billard A. Planar Solid Oxide Fuel Cell: Electrolyte Deposited by Reactive Magnetron Sputtering and Cell Test, Fuel Cells 2011:11;158.

[22] Hidalgo H., Thomann A.-L., Lecas T., Vulliet J., Wittmann-Teneze K., Damiani D., Millon E., Brault P. Optimization of DC Reactive Magnetron Sputtering Deposition Process for Efficient YSZ Electrolyte Thin Film SOFC. Fuel Cells 2013:13;279.

[23] Janardhanan V.M., Heuveline V., Deutschmann O. Three-phase boundary length in solidoxide fuel cells: A mathematical model. J Power Sources 2008:178;368. 


\section{Figure Captions.}

Figure 1. RBS experimental and simulated spectra of Ni-YSZ thin film. Silicon substrate.

Figure 2.- Top view (a) and cross-section (c) of the as-deposited thin film and after hydrogenannealing $(\boldsymbol{b}, \boldsymbol{d})$. Silicon substrate.

Figure 3.- XRD diagrams of Ni-YSZ thin films as-deposited and after hydrogen-annealing (red and blue peaks are due to YSZ and Ni respectively). Silicon substrate.

Figure 4: Cross-section of thin films after procedures i (a), ii (b) and iii (c) respectively. YSZ substrate.

\section{Table Captions.}

Table 1.- Concentrations of elements in the thin film.

Table 2.- Surface conductivity of thin film anodes 
Porous, robust highly conducting Ni-YSZ thin film anodes prepared by magnetron sputtering at oblique angles for application as anodes and buffer layers in solid oxide fuel cells

Table 1.- Concentrations of elements in the thin film.

\begin{tabular}{|l|l|l|l|l|}
\hline & $\begin{array}{l}\text { Thickness } \\
\left(\mathbf{1 0} \mathbf{a t}^{\mathbf{1 5}} \mathbf{c m}^{\mathbf{2}}\right)\end{array}$ & $\begin{array}{l}\text { Ni } \\
(\% \text { at. })\end{array}$ & $\begin{array}{l}\text { Y+Zr } \\
(\% \text { at. })\end{array}$ & $\begin{array}{l}\text { O } \\
(\% \text { at. })\end{array}$ \\
\hline YSZ:Ni & $19500 \pm 1000$ & $34.0 \pm 3.0$ & $6.5 \pm 0.8$ & $59.5 \pm 5.0$ \\
\hline
\end{tabular}

Table 2.- Surface conductivity of thin film anodes

\begin{tabular}{|c|c|}
\cline { 2 - 2 } \multicolumn{1}{c|}{} & Conductivity (S/cm) \\
\hline $800^{\circ} \mathrm{C}$, dry $\mathrm{H}_{2}$ & 2.40 \\
\hline $800^{\circ} \mathrm{C}, 3 \% \mathrm{H}_{2} \mathrm{O} / \mathrm{H}_{2}$ & 2.45 \\
\hline $900^{\circ} \mathrm{C}$, dry $\mathrm{H}_{2}$ & 2.86 \\
\hline $900^{\circ} \mathrm{C}, 3 \% \mathrm{H}_{2} \mathrm{O} / \mathrm{H}_{2}$ & 2.96 \\
\hline
\end{tabular}

